\title{
Use of topical local anesthetics to control pain during treatment of hoof lesions in dairy cows
}

\author{
G. T. Stilwell, ${ }^{1 *}$ A. M. Ferrador, ${ }^{1}$ M. S. Santos, ${ }^{1}$ J. M. Domingues, ${ }^{1}$ and N. Carolino ${ }^{2}$ \\ ${ }^{1}$ Animal Behavior and Welfare Laboratory, Center for Interdisciplinary Research in Animal Health, Faculty of Veterinary Medicine, \\ Lisbon University, Lisboa, Lisboa 1300-477, Portugal \\ ${ }^{2}$ Instituto Nacional de Investigação Agrária e Veterinária, I.P., Unidade Estratégica de Investigação e Serviços de Biotecnologia \\ e Recursos Genéticos, Polo de Investigação da Fonte Boa, Vale de Santarem 2005-048, Portugal
}

\section{ABSTRACT}

Hoof pathologies in dairy cows have a major effect on both production and animal welfare. Trimming of excess or diseased hoof tissue is essential for the treatment of many of these conditions. Trimming hoof lesions can cause severe pain, resulting in adverse behavioral responses with risk for animal and human safety. Interventions are usually carried out by nonveterinary technicians in the absence of pain management training. Pain control during trimming is not only an ethical obligation but also allows for better manipulation and more meticulous treatment. The aim of this study was to test the efficacy of Tri-Solfen (Bayer Australia Ltd., Pymble, NSW, Australia), a combination of local anesthetics in a topical gel form, containing lidocaine, bupivacaine, adrenaline, and cetrimide, for the treatment of pain associated with trimming of hoof lesions. Sixty-two Holstein-Frisian cows were selected for trimming at the drying-off period and were visually scored for lameness before entering the chute. After diagnosis of the hoof lesion but before deep trimming was initiated, each animal was randomly distributed to 2 groups: C, usual trimming with no pain control, and $\mathrm{T}$, trimming with a local anesthetic formulation being applied immediately after live corium was exposed. During curative trimming, behavior observation was conducted by 2 observers blind to treatment. In 27 cows, algometry measurements were performed before and after the procedure to assess animal reaction to pressure. Lameness scoring was again performed as the cow left the chute. Nonparametric tests and ANOVA were performed. Results showed that use of the topical anesthetic formulation significantly reduced reaction to trimming and lameness score after trimming when compared with nontreated animals. Algometry values

Received October 9, 2018.

Accepted March 12, 2019.

*Corresponding author: stilwell@fmv.ulisboa.pt showed increased pressure threshold after application of topical anesthetics. This study suggests that the use of topical local anesthesia with lidocaine and bupivacaine helps reduce pain associated with corrective trimming of severe hoof lesions, enhancing animal welfare and potentially ensuring safety of trimmers.

Key words: lameness, animal welfare, pain management, hoof lesion, topical local anesthetic

\section{INTRODUCTION}

Lameness is considered to be the single most important welfare problem in dairy cows due to its high prevalence and being a source of prolonged suffering (Whay and Shearer, 2017). Lame dairy cows experience some or all of the following signs: pain and discomfort; disturbed resting, feeding, and social patterns; reduced fertility; lowered milk yields; and an increased likelihood of being culled (Garcia et al., 2011; Alawneh et al., 2012; Bruijnis et al., 2012; Huxley, 2013). Acute but especially chronic pain are the main factors accountable for these effects. Even brief intervals of acute pain can induce long-term neuronal remodeling and sensitization, chronic pain, and lasting psychological distress (Anderson and Muir, 2005). Lame cows have reduced nociceptive thresholds consistent with the hyperalgesia that is associated with tissue lesion and concurrent inflammation (Coetzee et al., 2017). In cows with hoof horn lesions, pain at the site and surrounding areas (primary and secondary peripheral hyperalgesia) was shown to be present up to $28 \mathrm{~d}$ after treatment (Whay et al., 1998).

In dairy cows, gait alterations are usually the main clinical manifestation of discomfort or pain caused by hoof lesions (Van Nuffel et al., 2015). Methods to score lameness usually include changes in gait, back arch, head bob, posture, and other behavior changes (Sprecher et al., 1997; Flower and Weary, 2009; Shearer et al., 2013; Van Nuffel et al., 2015).

For most hoof horn lesions (e.g., sole ulcer, toe ulcer, and white line disease), trimming is the most impor- 
tant component of treatment. However, trimming that extends to the pododerm usually causes or exacerbates pain, as well as triggering local bleeding. Cows will sometimes react intensely to these procedures, including debris and necrotic tissue removal, which can be a safety issue for trimmers (Becker et al., 2014). Likewise, pain arising from pressure of the skeleton through the third phalanx on a damaged or destroyed sole is likely to persist after trimming (Stoddard and Cramer, 2017).

In some countries it is required that a veterinarian provide analgesia for painful procedures. However, the reality is that most hoof trimmers or farmers treat hoof lesions without consulting a veterinarian and without any pain management (Horseman et al., 2013). Even when a veterinarian is involved, local anesthetics are very seldom used (Becker et al., 2013).

The reasons for trimmers not to use analgesia include time and technical competence required for effective nerve block or for regional intravenous anesthesia, stoic temperament of cows that may not show signs of pain, human unwillingness to value the level of pain, cost of analgesic drugs, and withdrawal times for milk (Becker et al., 2014).

Our study aimed to determine, through lameness scoring, behavior assessment during trimming and reaction to pressure with a digital algometer, if topical application of local anesthetics during curative hoof trimming could combine practicability with efficacy in reducing pain while increasing human and animal safety.

Tri-Solfen (Bayer Australia Ltd., Pymble, NSW, Australia) is a "spray and stay" topical anesthetic formulation containing lidocaine for rapid onset wound anesthesia, bupivacaine as a long-acting local anesthetic to provide a prolonged duration of effect, adrenalin to concentrate the anesthetic effect at the wound site and reduce hemorrhage, and cetrimide to provide wound antisepsis, formulated in a viscous gel base. Nonspecialized personnel can easily apply it as a once-only application. Efficacy and welfare studies in mulesing, castration, and tail docking in lambs and castration in calves have shown that Tri-Solfen assists in the immediate alleviation of pain with prolonged effect, reducing both pain-related behavior, and wound pain responses from within $1 \mathrm{~min}$ up to and including $24 \mathrm{~h}$ after the procedures (Lomax et al., 2008; Paull et al., 2009; Espinoza et al., 2013; Lomax and Windsor, 2013).

\section{MATERIALS AND METHODS}

All procedures were approved under the Direcção Geral de Alimentação e Veterinária (Lisbon, Portugal)
Permission no. 49/ECVPT/2017 and the Ethics and Animal Welfare Committee of the Faculty of Veterinary Medicine, Lisbon University, reference 003/2018.

The studies were performed in 2 stages: the beginning of 2017 and then from September 2017 to February 2018.

\section{Study Design}

Animals included in this study belonged to 3 dairy herds kept in freestall stables with no access to pasture. Herd sizes were 1,000, 800, and 500 cows in milk. Feeding (TMR based on corn silage), breed (Holstein-Friesian), and general management were similar. Regular footbathing was carried out and functional trimming was done to all cows being dried off.

The inclusion criteria for the study were clinically lame cows at the end of lactation presenting sole ulcers, toe ulcers, or white line disease, needing curative trimming. Cows with chronic lameness, previously treated lesions, or presenting deep infected lesions or digital skin diseases were not included.

Treatment was undertaken with Tri-Solfen, a commercially available topical anesthetic, hemostatic, and antiseptic formulation for the alleviation of pain in production animals. It consists of lidocaine hydrochloride $(40.6 \mathrm{~g} / \mathrm{L})$, bupivacaine hydrochloride $(4.5 \mathrm{~g} / \mathrm{L})$, adrenaline acid tartrate $(24.8 \mathrm{mg} / \mathrm{L})$, and cetrimide $(5.0 \mathrm{~g} / \mathrm{L})$ in a gel base. An innocuous gel based on monopropylene glycol used for ultrasound examinations was applied to control animals. No animals destined to produce milk for human consumption in the following $60 \mathrm{~d}$ were treated, as this was a condition presented by the Direcção Geral de Alimentação e Veterinária.

Two different working teams were formed: one with 2 behavior assessors blind to treatment and the other with 2 operators that randomly selected lame cows for inclusion in treatment groups (see below) and performed the trimming and algometry. Trimming was performed by an experienced veterinarian using a modified Dutch 5-step trimming technique (Al Manning and Bell, 2016).

Dairy farmers were asked to select cows needing trimming at the end of lactation. Only cows showing lameness were selected for the study, and the level of lameness was scored by both teams independently from 1 to 5 [adapted from the Sprecher et al. (1997) lameness scoring system; Table 1] when taken to a fixed steel walk-through chute with an electric motor to lift the limbs and a band going under the chest. The hind legs were lifted by means of a strap placed above the hock, and the front limb was tied by the metacarpus to 
Table 1. Lameness score (adapted from Sprecher et al., 1997, with permission from Elsevier) and pain-related behaviors scored during trimming

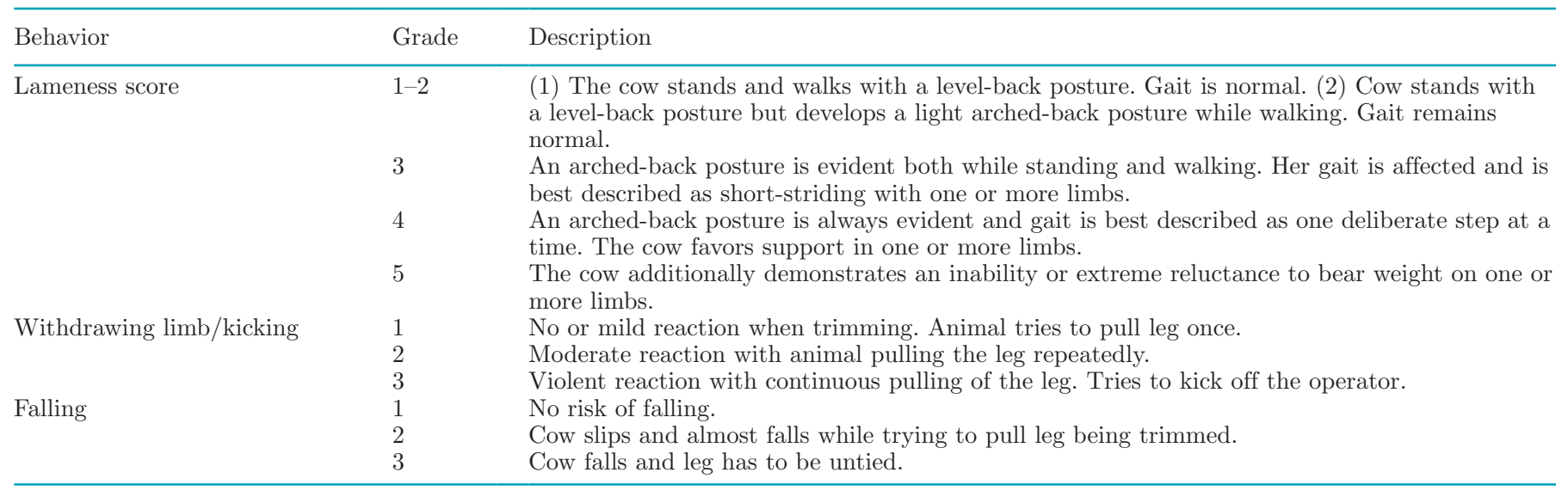

a wooden base at the side of the chute. In both cases movement of the leg was still possible, although limited. Cleaning and superficial trimming were performed until a lesion was clearly identified. Trimming continued until there was exposure of pododerm, granulation tissue, bleeding, or signs of pain.

When there was exposure of the pododerm and the lesion was considered suitable for the study (see inclusion criteria), cows were randomly distributed to 1 of 2 groups [Tri-Solfen group (T) or control group (C)] by taking a code paper from a bag. The affected limb and hoof were noted and the lesion was described, photographed, and measured using a caliper. Tri-Solfen or the innocuous gel was then applied until the wound and the exposed corium were completely covered. The application of Tri-Solfen was repeated if trimming had to go very deep, if more invasive procedures were needed, such as removal of necrotic, hemorrhagic, or granulation tissue; if a new lesion was found; or if bleeding had to be controlled by using gauze swabs. Care was taken to ensure that the lesion was covered by the gel for a least 1 min before the trimming continued. The total quantity of Tri-Solfen used was registered in milliliters.

An ethogram was completed during trimming, grading the following pain-related behaviors from 1 to 3 (Table 1): trying to withdraw limb or kicking, falling on one or more limbs, and vocalization. Because no cow vocalized, this behavior was later withdrawn from the analysis.

In very severe cases with exposure of significant areas of sensitive corium, a wooden block on the opposite hoof, an antibiotic/antiseptic spray, and a systemic nonsteroidal anti-inflammatory drug were used (flunixin-meglumine, carprofen, or tolfenamic acid, at the licensed dosages). Lameness was again scored (Table 1) as the cow was led to a nearby pen.

\section{Algometry}

For the second stage of the study, a digital algometer (Force Ten FPX, Wagner Instruments, Greenwich, $\mathrm{CT}$ ) was purchased. Once a lesion was identified, the algometer was pressed against the center and a reading was obtained when the cow moved to withdraw the limb. Two readings were done for each lesion at each moment, and the average was used for analysis. Pressure was measured in kilogram-force. Algometry was done at 3 moments: before, when the lesion was exposed; after, 1 min after applying Tri-Solfen or the innocuous gel; and end, after trimming and before lowering the leg. Values at "after" and "end" moments were subtracted from "before" values (considered baseline) to evaluate the variance due to trimming and treatment.

\section{Study Population}

Sixty-two dairy cows were included and submitted to the full protocol. Twenty-nine lame cows were included in the $\mathrm{C}$ group, presenting the following hoof lesions: 2 cases of white line disease, 23 cases of sole ulcer, and 4 cases of toe ulcer. Thirty-three lame cows were selected for the T group, with the following hoof lesions: 3 cases of white line disease, 24 cases of sole ulcer, 5 cases of toe ulcer, and 1 case of white line disease concomitant with a sole ulcer. Differences in the number of animals in each group are the result of aleatory drawing as no animal selected was later excluded from the study.

Algometry testing was performed only in 27 cows (8 from C group and 19 from $\mathrm{T}$ group). Several logistic reasons led to a very large difference in number of cows in the algometry groups: random selection, problems with the instrument, and baseline data loss in a set 
of cows that had to be removed from the statistical analysis.

\section{Statistical Analysis}

Data collection was performed using Microsoft Excel (version 2010; Microsoft Corp., Redmond, WA). Statistical analysis was performed with the SAS System (version 9.4; SAS Institute Inc., Cary, NC), using parametric and nonparametric tests. The variables submitted to statistical analysis were lameness score before and after trimming, reaction during trimming (withdrawing/kicking and falling), pressure thresholds, and variance across time. Lameness score, pain-related behaviors, and pressure thresholds were compared between groups and across time within each group.

Analysis of variance of lameness score was achieved through the SAS general linear model procedure (PROC GLM) with a model including groups and time effects. Algometry data were combined for all different podal pathologies assessed during the study. Analysis of variance was performed to $\mathrm{C}$ and $\mathrm{T}$ groups at before, after, and end moments, and also for differences between moments: after-before, end-after, and end-before. The GLM procedure of SAS and a model with group and moment effects were used for statistical analysis to compare groups and moments within each group. Means were estimated using the LSMEANS procedure

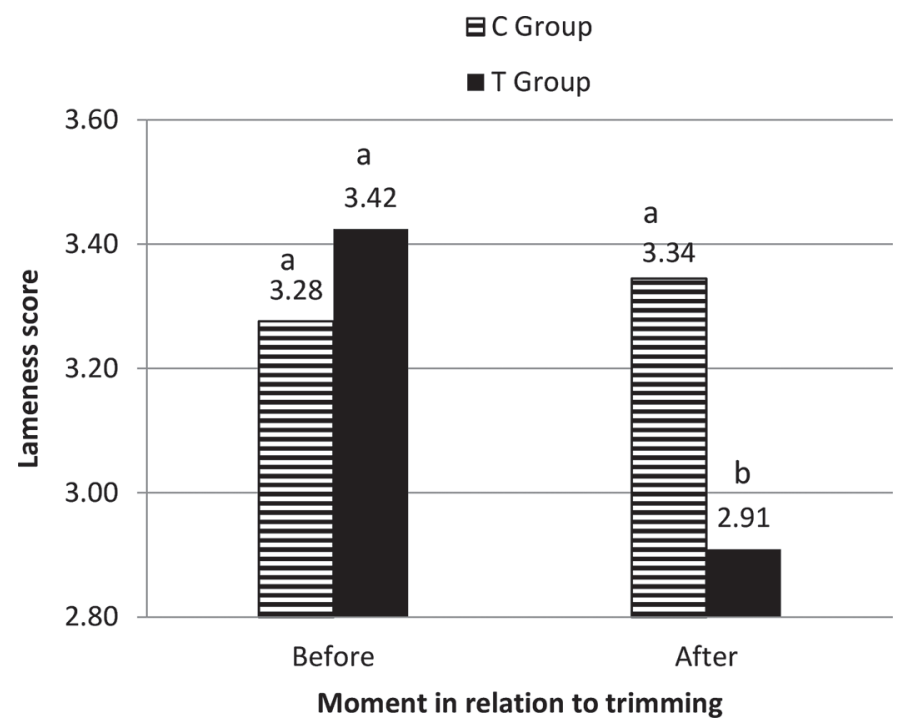

Figure 1. Average lameness score (5 point scale) in cows from $\mathrm{C}$ group (not treated) and T group (treated with Tri-Solfen, Bayer Australia Ltd., Pymble, NSW, Australia), before entering the chute for hoof trimming and when exiting after trimming. Different letters indicate significance at $P<0.05$. of SAS, and $P$-values less than 0.05 were considered significant for a confidence level of $95 \%$.

\section{RESULTS}

No significant inter-observer differences were found when assessing lameness or pain-related behaviors during trimming. Also, no differences in lesion dimension were found between groups: $6.07 \pm 2.97 \mathrm{~cm}^{2}$ and 5.75 $\pm 2.91 \mathrm{~cm}^{2}$ for $\mathrm{T}$ and $\mathrm{C}$ groups, respectively. Variables such as limb (front or hind), hoof (lateral or medial), or type of lesion (sole ulcer, toe ulcer, or white line disease) did not affect behavior or lameness score in any of the groups.

The total volume of Tri-Solfen applied varied between 4 and $14 \mathrm{~mL}$ with an average of $6.5 \mathrm{~mL}$. A correlation between lesion size and volume of product was not found because quantity applied considered not only the size but also the type of lesion and the occurrence of bleeding.

\section{Lameness Assessment}

Lameness score before trimming and lameness score after trimming were compared within both groups and between groups. For the $\mathrm{C}$ group, no significant differences $(P=0.692)$ were found between the 2 moments of assessment, with means $3.28 \pm 0.12$ before trimming and $3.35 \pm 0.12$ after trimming. For the T group, lameness score when leaving the chute $(2.91 \pm 0.12)$ was significantly lower $(P<0.01)$ than before trimming $(3.42 \pm 0.12)$ and significantly lower than both scores in the $\mathrm{C}$ group $(P<0.01$; Figure 1$)$.

The effect of the wooden blocks placed on the contralateral healthy hoof ( 2 in the $\mathrm{T}$ group and 3 in the $\mathrm{C}$ group) was negligible as removal from the analysis did not change the results.

\section{Pain-Related Behaviors}

For the analysis of the variables withdrawing/kicking and falling, all animals were included. When comparing groups, significant differences were found, with the $\mathrm{T}$ group animals showing fewer withdrawing/kicking scores $(P<0.01)$ and fewer falling scores $(P<0.05$; Figure 2).

\section{Algometry}

A total of 27 animals were included in the analysis of the algometry values during the second stage of this study when the digital algometer was purchased: 8 cows in the $\mathrm{C}$ group and 19 in the $\mathrm{T}$ group. Random lo- 


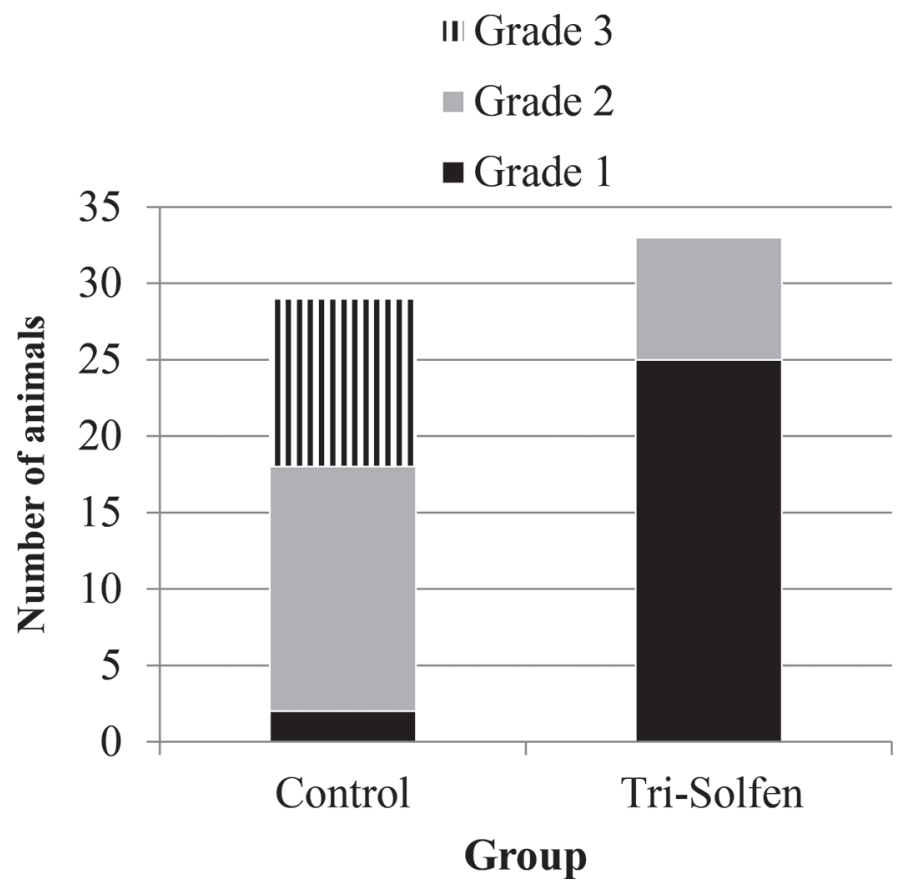

Figure 2. Number of animals showing different grades of withdrawing/kicking behavior in control and Tri-Solfen (Bayer Australia Ltd., Pymble, NSW, Australia) groups.

gistical problems and also loss of some baseline records explain the difference in numbers between groups, as explained above. Data for all type of lesions were combined to determine the differences in algometry values with or without Tri-Solfen application. From the 27 cows included in this part of the study, 10 cows from $\mathrm{T}$ group at moment "after" and 2 cows from $\mathrm{T}$ group at moment "end" did not get an algometer reading due to logistical difficulties (e.g., need to speed up the trimming or to quickly release the animals from the chute) or loss of data.

No differences were found between the algometer values of the 2 groups before trimming and at the end. However, significant differences were found in algometry values between $\mathrm{C}$ and $\mathrm{T}$ groups at the "after" period $(P<0.05)$. The pressure threshold variation between "before" and "end" was also different between treatments, with the $\mathrm{T}$ group showing a significant increase in pressure threshold $(P<0.05$; Table 2$)$. No variation in values across time was observed in the $\mathrm{C}$ group, but the $\mathrm{T}$ group showed a significant increase in pressure threshold after applying Tri-Solfen (after) compared with baseline (before).

\section{DISCUSSION}

Curative trimming of hoof lesions in dairy cows can inflict severe pain (Chapinal et al., 2010; Stoddard and
Cramer, 2017), and this is acknowledged by farmers, trimmers, and practitioners (Becker et al., 2013). However, these routine painful procedures are frequently performed without anesthesia (Becker et al., 2014), causing immediate pain and exacerbating a hyperalgesic state that is often associated with hoof lesions (Whay et al., 1998). Pain control may be difficult or neglected in farm animal practice, especially in countries with large livestock populations and where veterinary services are unavailable to treat individual animals (Windsor et al., 2016). In a survey undertaken in Switzerland, Becker et al. (2014) reported that no veterinary consultation or local anesthesia occurred when common painful interventions on the feet of cattle were performed, in more than half of the herds (52\%). This number is probably much larger in other countries where legislation is omissive or more permissive.

Anesthesia of the feet for painful trimming procedures or surgery is usually achieved through a ring block in which a local anesthetic is injected at multiple sites around the limb or by an intravenous regional anesthesia under a tourniquet (Edmondson, 2008; Coetzee et al., 2017). Both of these procedures have to be performed by a veterinarian and are time consuming.

The development of effective and practical pain management tools must be given high priority to effectively decrease animal suffering in dairy farms. Yet, commercially available pain-alleviating options that meet the practical and economic constraints of production animal husbandry are currently lacking (Lomax et al., 2008). In Australia, an affordable and practical solution for pain alleviation during painful procedures has been proposed for incorporation into routine farm management practices (Lomax and Windsor, 2013; Windsor et al., 2016).

Topical anesthesia, applied during and immediately after the procedure, has previously been found to be practical and effective for reducing postoperative pain associated with surgical husbandry procedures, such as mulesing in sheep (Lomax et al., 2008; Paull et al., 2009) and dehorning and castration in calves (Espinoza et al., 2013; Lomax and Windsor, 2013). These findings have a major welfare effect for livestock undergoing painful procedures and suggest that the application on hoof lesions after pododerm exposure could be a practical solution for pain management during curative trimming of lame dairy cows.

Our results show that lameness after trimming is significantly lower than before trimming in animals treated with the topical product Tri-Solfen, suggesting that by blocking nociceptive fibers around the lesion the animal will allow some weight on the affected limb. Although lameness is not abolished because full anesthesia is not likely, some numbing of the area probably 
occurs. This improvement on lameness score did not occur for the $\mathrm{C}$ group, suggesting that trimming alone does not relieve pain or can even inflict and exacerbate pain. This last idea could not be statistically demonstrated in our study, although the numerical reduction in pressure threshold in $\mathrm{C}$ group does suggest some hyperalgesia.

A positive long-term effect of reducing pain during trimming is probable. Local anesthetic agents act by reversibly blocking conduction of signals responsible for the sensation of pain, not only effecting wound anesthesia, but also preventing or reducing the subsequent pain escalation response that leads to central hyperalgesia (Whay et al., 1998; Lomax et al., 2008; Coetzee et al., 2017). This means that chronic pain may be reduced by reducing a wind-up effect caused by very painful trimming (Hellyer et al., 2007). However, further studies on the extended effects of painful trimming are required.

Observation of behavior responses to an acute painful stimulus is an objective, repeatable, and readily measurable form of assessing pain, commonly used for grading pain in many trials, allowing the assessor to distinguish between various analgesic interventions (Lomax et al., 2008; Stilwell et al., 2008; Stilwell et al., 2014; Stoddard and Cramer, 2017). To assess painrelated responses, kicking or withdrawing the limb and falling down were evaluated by a group of 2 observers blind to treatment, increasing repeatability. Both kicking/withdrawing and falling were significantly lower for the $\mathrm{T}$ group compared with the $\mathrm{C}$ group. A less intense exhibition of pain-related behaviors during curative trimming after the application of Tri-Solfen suggests that the local anesthetics are effective in reducing pain sensation (Lomax et al., 2008). A significant treatment effect on pain related-behaviors has previously been proven following castration, with Tri-Solfen-treated calves expressing significantly less pain than untreated calves (Lomax and Windsor, 2013).

Mechanical nociceptive threshold tests, such as algometry, are objective measures of the responsiveness of animals or humans to a noxious stimulus (Whay et al., 1998; Raundal et al., 2014; Pelfort et al., 2015; Lane and Hill, 2016). These techniques may be used to record changes in the nociceptive threshold associated with physical injury or surgical trauma. The decrease in pressure threshold is referred to as a demonstration of an exaggerated sensitivity to pain or hyperalgesia. In our study, algometry values increased in the cows submitted to corrective trimming after topical anesthetic application ( $\mathrm{T}$ group) when compared with animals summited to the same procedure without any pain management (C group), which maintained algometry values on the same range. This demonstrates a higher nociceptive threshold in the treated group because tolerance to pressure was higher. Such conclusions are reinforced by the rise in algometry values between the "before" and "end" of treatment in the T group, suggesting a hypoalgesic state. In the $\mathrm{C}$ group, an apparent reduction in pressure threshold occurred after the first trimming and the application of the innocuous gel, suggestive of postprocedural hyperalgesia (Table 2). However, this did not reach statistical significance, which may have been due to the low number of animals remaining for analysis in this group. No evidence was observed of improvement in the nociceptive threshold status due to removing pressure by trimming. Previous studies using nociceptive threshold testing to evaluate wound sensitivity after application of topical anesthetics corroborate these findings. Espinoza et al. (2013) stated that calves treated with topical anesthesia were more likely to show no response to stimulation than calves without topical anesthesia, up to $90 \mathrm{~min}$ after dehorning. Also in calves, treatment with topical anesthesia had a significant effect on pain threshold after castration, with response being significantly lower than in untreated calves, indicating that a significant wound anesthesia was achieved (Lomax and Windsor, 2013).

Because algometry assessment was only implemented in a second stage of this trial, the number of animals tested was smaller. Additionally, chance and the loss of some baseline values, resulting in the removal of animals from the analysis, especially from the C group,

Table 2. Least squares means $( \pm \mathrm{SE})$ from algometry evaluation on 3 separate moments and the subtraction between values at these moments (e.g., period 1-2 corresponds to "before" minus "after" values) ${ }^{1}$

\begin{tabular}{|c|c|c|c|c|c|c|}
\hline Group & Before (1) & After (2) & End (3) & Period 1-2 & Period 1-3 & Period 2-3 \\
\hline
\end{tabular}

\footnotetext{
${ }^{\mathrm{a}, \mathrm{b}}$ Different lowercase superscript letters in the same column indicate significance at $P<0.05$.

${ }^{\mathrm{A}, \mathrm{B}}$ Different uppercase superscript letters in the same row indicate significant differences between periods at $P<0.05$.

${ }^{1}$ Pressure in kilogram-force. $\mathrm{C}=$ control group, not treated; $\mathrm{T}=$ treated with Tri-Solfen (Bayer Australia Ltd., Pymble, NSW, Australia).
} 
reduces the robustness of these findings. However, they still indicate that an increase in pressure threshold occurs in animals treated with the local anesthetics. We recommend that an algometry study with a larger control group should be performed to confirm these results.

Application of this product was shown to be easy and the effect almost immediate. Because it is an inexpensive and quick method of achieving some analgesia in the areas being severed, the product will probably be well accepted by farmers, trimmers, and veterinarians concerned about the pain caused when performing curative trimming in hooves of dairy cows (Becker et al., 2014). Other potential applications for this product could be pain management when treating foot lesions in beef cattle (e.g., feedlot) and also small ruminants.

\section{CONCLUSIONS}

Results from this study indicate that significant alleviation of pain can be achieved in dairy cows during and immediately after curative hoof trimming, using a commercially available spray-on gel with lidocaine and bupivacaine. Hence, the use of topical local anesthesia, such as Tri-Solfen, may be well-suited and accepted in production animal farming because of its low cost, practicality, and easy application. Not only animal welfare will be enhanced, but also potentially greater safety for the hoof trimmer will be accomplished due to less aggressive behavior reaction of the animal.

\section{ACKNOWLEDGMENTS}

We acknowledge the funding by Project Unidade de Investigação (UID)/Ciências Veterinárias (CVT)/00276/2019 (CISAA-Center for Interdisciplinary Research in Animal Health, Lisbon, Portugal) and the support from Animal Ethics Pty Ltd. (Australia). The authors also thank the farmers for their participation in this study.

\section{REFERENCES}

Al Manning, S. M., and N. J. Bell. 2016. Evidence base behind foot trimming in UK dairy cattle. Livestock (Lond.) 21:6-14.

Alawneh, J. I., M. A. Stevenson, N. B. Williamson, N. Lopez-Villalobos, and T. Otley. 2012. The effect of clinical lameness on liveweight in a seasonally calving, pasture-fed dairy herd. J. Dairy Sci. 95:663-669. https://doi.org/10.3168/jds.2011-4505.

Anderson, D. E., and W. M. Muir. 2005. Pain management in cattle. Vet. Clin. North Am. Food Anim. Pract. 21:623-635.

Becker, J., M. Reist, K. Friedli, D. Strabel, M. Wüthrich, and A. Steiner. 2013. Current attitudes of bovine practitioners, claw-trimmers and farmers in Switzerland to pain and painful interventions in the feet in dairy cattle. Vet. J. 196:467-476. https://doi.org/10.1016/ j.tvjl.2012.12.021.
Becker, J., M. Reist, and A. Steiner. 2014. Factors influencing the attitudes of cattle veterinarians, farmers, and claw trimmers towards the pain associated with the treatment of sole ulcers and the sensitivity to pain of dairy cows. Vet. J. 200:38-43. https://doi.org/ 10.1016/j.tvjl.2014.01.016.

Bruijnis, M. R. N., B. Beerda, H. Hogeveen, and E. N. Stassen. 2012. Assessing the welfare impact of foot disorders in dairy cattle by a modeling approach. Animal 6:962-970. https://doi.org/10.1017/ S1751731111002606.

Chapinal, N., A. M. De Passille, and J. Rushen. 2010. Correlated changes in behavioral indicators of lameness in dairy cows following hoof trimming. J. Dairy Sci. 93:5758-5763. https://doi.org/10 .3168/jds.2010-3426.

Coetzee, J. F., J. K. Shearer, M. L. Stock, M. D. Kleinhenz, and S. R. van Amstel. 2017. An update on the assessment and management of pain associated with lameness in cattle. Vet. Clin. North Am. Food Anim. Pract. 33:389-411. https://doi.org/10.1016/j cvfa.2017.02.009.

Edmondson, M. A. 2008. Local and regional anesthesia in cattle. Vet. Clin. North Am. Food Anim. Pract. 24:211-226. https://doi.org/ 10.1016/j.cvfa.2008.02.013.

Espinoza, C., S. Lomax, and P. Windsor. 2013. The effect of a topical anesthetic on the sensitivity of calf dehorning wounds. J. Dairy Sci. 96:2894-2902. https://doi.org/10.3168/jds.2012-5954.

Flower, F. C., and D. M. Weary. 2009. Gait assessment in dairy cattle. Animal 3:87-95. https://doi.org/10.1017/S1751731108003194.

Garcia, E., J. Hultgren, P. Fällman, J. Geust, B. Algers, G. Stilwell, S. Gunnarsson, and H. Rodriguez-Martinez. 2011. Oestrous intensity is positively associated with reproductive outcome in high-producing dairy cows. Livest. Sci. 139:191-195. https://doi.org/10.1016/ j.livsci.2011.01.004.

Hellyer, P. W., S. A. Robertson, and A. D. Fails. 2007. Pain and its management. Pages 31-57 in Veterinary Anaesthesia and Analgesia. 4th ed. W. J. Tranquilli, J. C. Thurmon, and K. A. Grimm, ed. Blackwell Publishing, Ames, IA.

Horseman, S. V., H. R. Whay, J. N. Huxley, N. J. Bell, and C. S. Mason. 2013. A survey of the on-farm treatment of sole ulcer and white line disease in dairy cattle. Vet. J. 197:461-467. https://doi .org/10.1016/j.tvjl.2013.02.027.

Huxley, J. N. 2013. Impact of lameness and claw lesions in cows on health and production. Livest. Sci. 156:64-70. https://doi.org/10 $.1016 /$ j.livsci.2013.06.012.

Lane, D. M., and S. Hill. 2016. Pressure algometry measurement of canine muscular pain near the thoracolumbar junction: Evaluation of a modified technique. Vet. Anaesth. Analg. 43:227-234. https:/ /doi.org/10.1111/vaa.12308

Lomax, S., M. Sheil, and P. A. Windsor. 2008. Impact of topical anaesthesia on pain alleviation and wound healing in lambs after mulesing. Aust. Vet. J. 86:159-168. https://doi.org/10.1111/j.1751 $-0813.2008 .00285 . x$.

Lomax, S., and P. A. Windsor. 2013. Topical anesthesia mitigates the pain of castration in beef calves. J. Anim. Sci. 91:4945-4952. https: //doi.org/10.2527/jas.2012-5984.

Paull, D. R., C. Lee, I. G. Colditz, and A. D. Fisher. 2009. Effects of a topical anaesthetic formulation and systemic carprofen, given singly or in combination, on the cortisol and behavioural responses of Merino lambs to castration. Aust. Vet. J. 87:230-237. https:// doi.org/10.1111/j.1751-0813.2009.00429.x.

Pelfort, X., R. Torres-Claramunt, J. F. Sánchez-Soler, P. Hinarejos, J. Leal-Blanquet, D. Valverde, and J. C. Monllau. 2015. Pressure algometry is a useful tool to quantify pain in the medial part of the knee: An intra-and inter-reliability study in healthy subjects. Orthop. Traumatol. Surg. Res. 101:559-563. https://doi.org/10 .1016/j.otsr.2015.03.016.

Raundal, P. M., P. H. Andersen, N. Toft, B. Forkman, L. Munksgaard, and M. S. Herskin. 2014. Handheld mechanical nociceptive threshold testing in dairy cows-intra-individual variation, interobserver agreement and variation over time. Vet. Anaesth. Analg. 41:660-669. https://doi.org/10.1111/vaa.12159. 
Shearer, J. K., M. L. Stock, S. R. Van Amstel, and J. F. Coetzee. 2013. Assessment and management of pain associated with lameness in cattle. Vet. Clin. North Am. Food Anim. Pract. 29:135-156. https: //doi.org/10.1016/j.cvfa.2012.11.012.

Sprecher, D. J., D. E. Hostetler, and J. B. Kaneene. 1997. A lameness scoring system that uses posture and gait to predict dairy cattle reproductive performance. Theriogenology 47:1179-1187. https:// doi.org/10.1016/S0093-691X(97)00098-8.

Stilwell, G., M. S. Lima, and D. M. Broom. 2008. Effects of nonsteroidal anti-inflammatory drugs on long-term pain in calves castrated by use of an external clamping technique following epidural anesthesia. Am. J. Vet. Res. 69:744-750. https://doi.org/10.2460/ajvr .69.6.744.

Stilwell, G., H. Schubert, and D. M. Broom. 2014. Effects of analgesic use postcalving on cow welfare and production. J. Dairy Sci. 97:888-891. https://doi.org/10.3168/jds.2013-7100.

Stoddard, G. C., and G. Cramer. 2017. A review of the relationship between hoof trimming and dairy cattle welfare. Vet. Clin. North
Am. Food Anim. Pract. 33:365-375. https://doi.org/10.1016/j .cvfa.2017.02.012.

Van Nuffel, A., I. Zwertvaegher, L. Pluym, S. Van Weyenberg, V. M. Thorup, M. Pastell, and W. Saeys. 2015. Lameness detection in dairy cows: Part 1. How to distinguish between non-lame and lame cows based on differences in locomotion or behavior. Animals (Basel) 5:838-860. https://doi.org/10.3390/ani5030387.

Whay, H. R., and J. K. Shearer. 2017. The impact of lameness on welfare of the dairy cow. Vet. Clin. North Am. Food Anim. Pract. 33:153-164. https://doi.org/10.1016/j.cvfa.2017.02.008.

Whay, H. R., A. E. Waterman, A. J. F. Webster, and J. K. O'Brien. 1998. The influence of lesion type on the duration of hyperalgesia associated with hindlimb lameness in dairy cattle. Vet. J. 156:2329. https://doi.org/10.1016/S1090-0233(98)80058-0.

Windsor, P. A., S. Lomax, and P. White. 2016. Progress in pain management to improve small ruminant farm welfare. Small Rumin. Res. 142:55-57. https://doi.org/10.1016/j.smallrumres.2016.03 .024 . 